\title{
Revisiting transdermal scopolamine for postoperative nausea and vomiting
}

REVIEW

\author{
Joseph V Pergolizzi ${ }^{1-3}$ \\ Robert B Raffa ${ }^{4}$ \\ Gianpietro Zampogna ${ }^{5}$ \\ Hani Michael Annabi ${ }^{6}$ \\ Thomas J Pallaria ${ }^{7}$ \\ Robert Taylor 5,6
}

'Department of Medicine, Johns Hopkins University School of Medicine, Baltimore, MD, ${ }^{2}$ Department of Pharmacology, Temple University School of Medicine, Philadelphia, PA, ${ }^{3}$ Association of Chronic Pain Patients, Houston, TX, ${ }^{4}$ Department of Pharmaceutical Sciences, Temple University School of Pharmacy, Philadelphia, PA, ${ }^{5}$ NEMA Research, Bonita Springs, FL, ${ }^{6}$ Public Health Department, Johns Hopkins University Krieger School of Arts and Sciences, Baltimore, MD, ${ }^{7}$ Department of Anesthesia, Barnabas Health-Newark Beth Israel Medical Center, Newark, NJ, USA

\section{Video abstract}

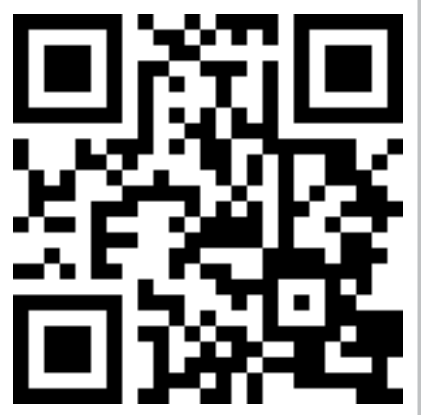

Point your SmartPhone at the code above. If you have a QR code reader the video abstract will appear. Or use: http://youtu.be/WhUqcM20gAU

Correspondence: Robert Taylor NEMA Research Inc., 3384 Woods Edge Circle, Suite 102, Bonita Springs,

FL 34134, USA

$\mathrm{Tel}+\mathrm{I} 2399084442$

Fax +l 2399084432

Email rtaylor@nemaresearch.com
This article was published in the following Dove Press journal:

Research and Reports in Transdermal Drug Delivery

13 August 2015

Number of times this article has been viewed

Abstract: Postoperative nausea and vomiting (PONV) and postdischarge nausea and vomiting (PDNV) in ambulatory patients remain serious problems that affect a substantial subset of surgical patients. Guidelines recommend that patients be stratified for risk, and patients at moderate-to-high risk be administered prophylactic PONV/PDNV therapy. Risk stratification on the four-point Apfel scale assigns one point for each of the following: female sex, nonsmoking status, history of PONV or motion sickness, and the use of postoperative opioids. Patients who score 2 or higher are considered to be at moderate-to-high risk. Other risk factors have been evaluated and discussed in the literature, such as type and duration of surgery. Surprisingly, although PONV/PDNV is more common in the first 24 hours after anesthesia, it may occur for days following surgery, and so, continuous treatment is advantageous. Transdermal scopolamine is a well-established agent with a history of safety and efficacy for PONV/PDNV prevention. Scopolamine is an anticholinergic agent that is generally well tolerated; side effects tend to be mild to moderate. The most frequently reported side effects with transdermal scopolamine are visual disturbances and dry mouth. Once adhered to the skin, the patch administers an initial dose and then a continuous dose of medication over 72 hours. Transdermal scopolamine is easy to administer, safe, effective, and relatively cost-effective, and it should be considered as an important tool to help prevent PONV/PDNV, whether administered as monotherapy or in combination with other agent(s).

Keywords: transdermal scopolamine, postoperative nausea and vomiting, antiemetic

\section{Introduction}

Despite many advances in surgical medicine in the past decade, postoperative nausea and vomiting (PONV) remains a problem. For example, in a survey of 400 surgical patients, $81 \%$ reported anxiety prior to surgery; $60.2 \%$ were specifically concerned that they might suffer postoperative nausea and/or vomiting. This was more than the $33.5 \%$ who were fearful that they might be paralyzed following surgery and was about the same as the $64.8 \%$ who had concerns that they would not wake up after surgery. ${ }^{1}$ In a well-known study, patients were asked to rank ten potential postoperative outcomes from least to most desirable. ${ }^{2}$ Patients ranked vomiting as the most undesirable of all postoperative outcomes, even more undesirable than gagging on the tracheal tube or experiencing postoperative pain. ${ }^{2}$ In a survey of 82 cesarean section patients, the three most undesirable postoperative outcomes were (in order): pain, vomiting, and nausea. ${ }^{3}$

Despite important work in elucidating the mechanisms of PONV and validation of risk-stratification algorithms for surgical patients, the "big little problem" first described 
by Dr Kapur back in 1991 persists. ${ }^{4}$ Approximately one out of every four surgical patients will experience some form of postoperative nausea with or without vomiting. ${ }^{5}$ While PONV is typically described as "postoperative" nausea and vomiting, it is important to distinguish it from postdischarge nausea and vomiting (PDNV). PDNV is quite likely underreported, as it occurs outside the clinical setting; patients who are suffering from PDNV may not report it. ${ }^{6}$ Thus, physicians may be surprised that in a survey of 248 surgical outpatients, postdischarge nausea occurred in $56.9 \%$ and postdischarge vomiting in $19.4 \% .^{7}$ In a large study of ambulatory surgery patients $(n=2,170)$, the overall incidence of PDNV was found to be $37 \% .{ }^{5}$ Similar to PONV, PDNV may negatively impact the patient.

PONV or PDNV can delay patient discharge, inhibit rehabilitation and recovery, cause patient distress and discomfort, and decrease patient satisfaction. ${ }^{8}$ It may also be associated with some relatively rare complications, such as wound dehiscence or aspiration of emesis. In addition, PDNV can be the cause of electrolyte imbalances, acid-base disorders, esophageal rupture, and acute elevations in blood pressure. ${ }^{9-11}$ The literature suggests that certain patients are at particularly high risk for PONV/PDNV. ${ }^{12}$ Surgical patients should be stratified for their risk of nausea and/or vomiting following surgery, and those at elevated risk should be administered prophylactic treatment.

Because of the importance and negative impact of PONV on patients, health care providers, and insurers, it is advantageous to assess treatment modalities on a regular basis. Updated guidelines for management of PONV were recently published. Now, about 18 months later, it is timely that we revisit the efficacy, timing, and safety of using transdermal scopolamine in PONV.

\section{Guidelines}

Multidisciplinary guidelines related to PONV were published in 2003 and 2007, and updated in 2014, ${ }^{13}$ in addition to guidelines of smaller scope addressing specific surgical populations. The primary objectives for PONV prevention are to decrease the rate of PONV, relieve patient discomfort and distress, increase patient satisfaction, and reduce health care costs by decreasing postoperative morbidity. ${ }^{14-17}$ The new broad 2014 guidelines recommend that clinicians evaluate surgical patients for their risk of PONV using validated metrics, reduce risk factors if possible, and administer PONV prophylactic therapy to adults at moderate risk of PONV and administer multimodal antiemetic therapy to high-risk patients. ${ }^{13}$ Certain risk factors, such as sex or age, cannot be modified. Prophylactic therapy is also appropriate for pediatric surgical patients at elevated risk of PONV, although pediatric risk factors differ somewhat from adult risk factors. ${ }^{18}$

Risk stratification is only a tool, because individual patients can still succumb to PONV without any risk factors. Thus, clinicians should always be prepared to offer rescue antiemetic therapy to patients following surgery. If prophylactic therapy fails, the clinician should consider the use of rescue antiemetic therapy. ${ }^{13}$

\section{Risk stratification for PONV}

Certain patients may be at markedly elevated risk for PONV or PDNV, with potential incidences as high as $80 \%$ compared to the general incidence of $30 \% \cdot{ }^{12,19,20}$ Apfel et al proposed a straightforward risk stratification algorithm that assigns one point for each of the following: female sex, nonsmoker, history of PONV (or motion sickness), and the use of opioids postoperatively. Thus, patients may score $0-4$ in terms of risk and their corresponding rate of PONV is projected to be $10 \%, 20 \%, 40 \%, 60 \%$, and $80 \%$, respectively. ${ }^{12}$ The guidelines consider a so-called "Apfel score" of 0-1 as low risk, 2-3 as medium risk, and 4 as high risk. ${ }^{13}$ The sensitivity and specificity of this algorithm are $65 \%$ and $70 \%$, respectively. ${ }^{13}$ Without diminishing the utility of this risk stratification tool, clinicians must be cognizant that PONV and PDNV can be multifactorial and many things may come into play that influence whether or not a patient will experience nausea and/or vomiting after surgery.

The strongest predictive factor for PONV is female sex (odds ratio [OR], 2.57; 95\% confidence interval [CI], $2.32-2.84) .^{5,21}$ The strongest anesthesia-related predictor is the use of a volatile anesthetic (OR, 1.82; 95\% CI, 1.56-2.13). Newer evidence suggests that younger age groups ( $\leq 50$ years) may be at higher risk (OR; 1.79; 95\% CI, 1.39-2.30), ${ }^{5}$ although age is not captured in some of the earlier risk assessment algorithms. Experts debate whether the type of surgery influences the PONV rates; it appears that cholecystectomy and gynecological surgery have substantially higher rates of PONV than many other types of surgery (OR, 1.90; 95\% CI, 1.36-2.68 and OR, 1.24; 95\% CI, 1.02-1.52, respectively). ${ }^{21}$ Moreover, a recent study of complications in cervicofacial rhytidectomy found that PONV occurred in 55 out of 108 patients, although PONV was relatively rare in patients who underwent midinferior face and cervical rhytidectomy. ${ }^{22}$ Thus, it appears that the type of surgery - and possibly its duration ${ }^{21}$ - may influence the PONV rates. The association of PONV with the use of a 
nasogastric tube remains disputed in the literature. ${ }^{13,23}$ Obesity and history of migraine are currently not thought to influence the PONV rates. ${ }^{13}$

Since PONV is such an unwelcome complication in surgical patients, it has been proposed that all surgical patients receive prophylactic antiemetic therapy. However, the majority of surgical patients will not develop PONV; exposing such a large subset of the surgical population to additional pharmacological therapy increases the risk of side effects and potential drug-drug interactions. Thus, the current approach is to stratify risk and provide prophylactic therapy to patients who are at moderate-to-high risk. Of course, the existence of a validated risk assessment tool does not preclude sound clinical judgment based on the individual patient's case. There may be other factors to consider when determining which patients should receive PONV prophylaxis. For example, PONV prophylaxis may be appropriate regardless of the patient's individual risk score if vomiting may pose a significant medical hazard (for instance, those with a jaw wired shut or those with elevated intracranial pressure) or in patients who are undergoing gastric or esophageal procedures.

\section{Risk assessment for PDNV}

PDNV is an increasing and urgent concern, because of the current migration of many surgeries and medical procedures to outpatient facilities and ambulatory surgery centers. PDNV is not as well described as PONV in the literature, ${ }^{24}$ and, indeed, may not be fully appreciated by clinicians. Since the majority of surgical procedures carried out in the US today are done as outpatient procedures (60\%), the risk assessment for PDNV is an important preoperative consideration. ${ }^{25}$

There is a separate Apfel algorithm for assessing the risk of PDNV, in which patients are assigned one point for each of the following: female sex, history of PONV, age $<50$ years, use of opioids in the postanesthesia care unit (PACU), and nausea in the PACU. In contrast to the PONV algorithm, ambulatory patients can score $0-5$, which is associated with a risk of PDNV of $10 \%, 20 \%, 30 \%, 50 \%, 60 \%$, and $80 \%$, respectively. ${ }^{5}$

In a prospective study of 248 surgical outpatients, different PDNV predictors were discussed. This study found the following variables to significantly predict PDNV in surgical outpatients: a history of PONV (OR, 3.5; range: 1.70-7.27), operating room time (OR, 2.19; range: 1.34-3.60), the use of ondansetron in the PACU (OR, 6.39; range: 1.65-24.79), and pain on the third to seventh days after surgery (OR, 1.67; range: $1.30-2.14) .{ }^{26}$ In this study group, patients were asked to record the incidence and severity of nausea and vomiting for the first 7 days after discharge. Although the risk of PDNV was highest on the first day after discharge (and decreased over time), PDNV sometimes occurred a few days after surgery. ${ }^{26}$ In this study, the prevalence of postdischarge nausea was $56.9 \% .^{7}$ In another study, of 100 ambulatory surgery patients, 37\% had PONV during hospitalization and $42 \%$ and $49 \%$ had PDNV by the first and third postoperative mornings, respectively. ${ }^{27}$ This suggests that the rate of PDNV may actually increase in the first few postoperative days. In a larger multicenter study ( $n=2,170$ adult ambulatory patients undergoing surgery under general anesthesia), PDNV occurred in 37\% of patients (PDNV was assessed only for the first 2 days after discharge). ${ }^{5}$

There may be genetic risk factors in PDNV. A singlecenter study of 80 postmenopausal women who underwent breast cancer surgery found that women with a certain serotonin transport gene (LA/LA genotypes) were at elevated risk for PDNV following surgery compared to women without this gene. Furthermore, women with this serotonin transport gene may experience PDNV for $\geq 1$ month after surgery $(21 \%$ reported PDNV at an average of 1 month after surgery). ${ }^{28}$ Prolonged PDNV in this study was associated with increased pain and heightened anxiety.

Clinicians should alert ambulatory patients upon discharge of the potential risks of PDNV and urge patients with PDNV to contact the clinic for antiemetic medications. It is possible that ambulatory patients experience unreported PDNV once discharged home. When PDNV is left untreated, the condition may prolong or compromise their recovery.

\section{Reducing the risk of PONV and PDNV}

Strategies to reduce the baseline risk of PONV or PDNV have been described in the literature. Among these strategies are the use of regional, rather than general, anesthesia, ${ }^{20,29}$ the use of propofol to induce and maintain anesthesia, ${ }^{30}$ avoiding nitrous oxide, ${ }^{31-33}$ avoiding volatile anesthetics, ${ }^{30,34}$ minimizing or avoiding the use of intraoperative and postoperative opioids, ${ }^{12,33-35}$ and assuring the patient adequate hydration. ${ }^{36,37}$ However, some risk factors cannot be controlled (sex, age), and some risk factors may be necessary to assure optimal overall outcomes. For that reason, risk stratification plus prophylaxis is the paradigm recommended in the guidelines.

\section{Prophylaxis of PONV and PDNV}

Numerous pharmacological options have been identified and appear in the guidelines for PONV and PDNV prophylaxis. The scopolamine patch is the only one available 
in a transdermal delivery system, which is to be applied the evening before surgery or, alternately, 2 hours prior to surgery (Figure 1). ${ }^{38,39}$ Scopolamine may be classified as an anticholinergic agent. Other classes of agents that may be used to prevent PONV or PDNV include dexamethasone, dopamine antagonists (such as droperidol), histamine antagonists, neurokinin antagonists, and serotonin antagonists (such as ondansetron). ${ }^{24}$

Transdermal scopolamine may be used as monotherapy, but it has also been an effective adjunctive agent to other antiemetic therapy, ${ }^{40}$ and it may help control nausea for postsurgical patients using a patient-controlled anesthesia system. ${ }^{41,42}$ Transdermal scopolamine may be included in combination therapy, but when it is used as monotherapy for PONV/PDNV prophylaxis, ondansetron, droperidol, and transdermal scopolamine are equally effective. ${ }^{43}$

\section{Brief pharmacology of transdermal scopolamine}

Scopolamine acts as a nonselective competitor to acetylcholine for muscarinic receptors (nonselective muscarinic antagonist) and has peripheral and central sedative, amnestic, and antiemetic effects. ${ }^{18}$ It appears to interrupt cholinergic messages from the vestibular nuclei to higher areas of the central nervous system.

Scopolamine is the first commercial agent available in a continuous ( 72 hours) transdermal delivery system. ${ }^{44,45}$ The small patch adheres directly to the skin in the hairless area behind the ear. A priming dose of scopolamine $(140 \mu \mathrm{g})$ is delivered and followed by a slower continuous release over the next 3 days $(0.5 \mathrm{mg} /$ day for 3 days $) .{ }^{18}$ In about 4 hours after patch application, scopolamine is detectable in the blood, with peak levels achieved around 24 hours. The elimination half-life of scopolamine in the transdermal system is about 9.5 hours. Transdermal scopolamine is available in branded and generic versions.

Scopolamine is absorbed and bound to plasma proteins; it undergoes hepatic conjugation and elimination of hydrophilic metabolites in the urine. About $5 \%$ of scopolamine is unchanged when excreted from the body. ${ }^{46}$ Scopolamine can penetrate the blood-brain barrier.

\section{Transdermal scopolamine: clinical efficacy}

The literature reports numerous studies documenting the efficacy of transdermal scopolamine as an effective antiemetic and/or PONV/PDNV prophylactic agent; some of these studies date back 25 years or more. ${ }^{44}$ In a systematic review of 25 randomized controlled trials $(n=3,298)$, when compared to placebo, transdermal scopolamine significantly reduced the patient's risk in the PACU of postoperative nausea (relative risk, 0.77 ; 95\% CI, 0.61-0.98, $P=0.03$ ), postoperative vomiting (relative risk, $0.68,95 \% \mathrm{CI}, 0.61-0.76, P<0.001$ ), and PONV (relative risk, $0.73 ; 95 \% \mathrm{CI}, 0.60-0.88, P=0.001$ ) in the first 24 hours following surgery. ${ }^{40}$ A slightly earlier systematic review ( 23 clinical trials, $n=1,963$ ) reported that out of 100 surgical patients receiving transdermal scopolamine, 17 will not experience postoperative vomiting who otherwise would have suffered this condition. ${ }^{39}$

A particular concern for cesarean section patients is the use of intrathecal morphine, which serves as an effective postoperative analgesic agent but is also associated with higher rates of PONV. In a study of 240 patients undergoing cesarean delivery with intrathecal morphine anesthesia, patients were randomized to receive transdermal scopolamine, $4 \mathrm{mg}$ ondansetron, or placebo at the time of cord clamping. ${ }^{47}$ The incidence of postoperative vomiting was least with transdermal scopolamine during 6-hour to 24-hour

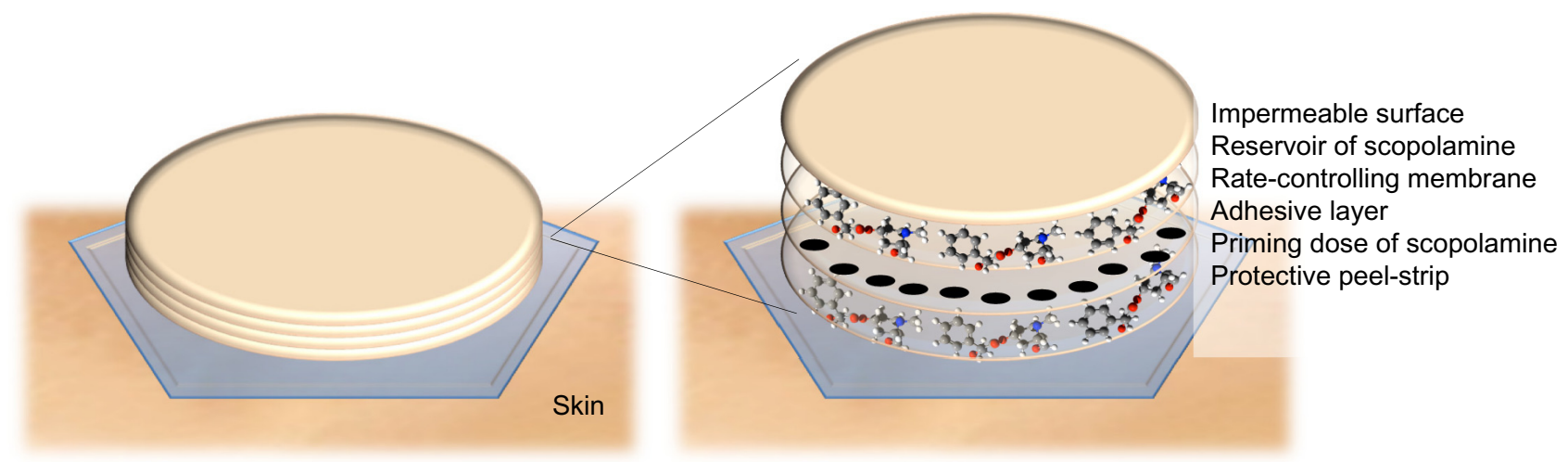

Figure I Upon application, an initial priming dose of scopolamine is released from within the adhesive layer in order to saturate binding sites on the skin. The subsequent delivery of scopolamine, from the reservoir, is determined by a rate-controlling membrane and is designed to produce stable plasma levels within a therapeutic range. 
period: $59.3 \%$ (placebo), $41.8 \%$ (ondansetron), and 40\% (transdermal scopolamine).

In a study of 150 surgical patients (80 major laparoscopic and 70 plastic surgery procedures), patients were randomized to receive a transdermal scopolamine or sham patch about an hour before entering the operating room. ${ }^{43}$ When surgery concluded, transdermal scopolamine patients were administered saline solution while the sham-patch patients were administered droperidol $1.25 \mathrm{mg}$ or ondansetron $4 \mathrm{mg}$. In the first 72 hours after surgery, there were no significant differences between the transdermal scopolamine, droperidol, or ondansetron groups in terms of postoperative vomiting or need for rescue medication. Transdermal scopolamine patients had significantly more dry mouth $(21 \%$ vs $3 \%$ for transdermal scopolamine versus the other two active agents, respectively). ${ }^{43}$

A retrospective analysis of 205 patients undergoing middle ear surgery identified 85 female patients with normal menstrual cycles and correlated their menstrual cycle to the PONV rates and medications. ${ }^{48}$ The investigators considered the periovulatory period (menstrual days 11-24) to be a risk factor for PONV. Transdermal scopolamine administered as PONV prophylaxis resulted in significantly lower rates of retching and vomiting $(P<0.05)$ in these patients and was associated with lower consumption of postoperative droperidol rescue medication $(0.4 \pm 0.7 \mathrm{mg}$ vs $1.4 \pm 1.5 \mathrm{mg}$, respectively, $P<0.01) .{ }^{48}$ The investigators reported that the reduced droperidol consumption associated with transdermal scopolamine was significant for women patients during the periovulatory period versus other times of the month $(1.4 \pm 1.3 \mathrm{mg}$ vs $0.3 \pm 0.05 \mathrm{mg}$, respectively, $P<0.005$ ). By contrast, the use of ondansetron reduced the mean consumption of droperidol from $1.4 \pm 1.5 \mathrm{mg}$ to $0.6 \pm 0.8 \mathrm{mg}$, respectively, $P<0.05 .{ }^{48}$

In a randomized study of 48 patients undergoing a gynecologic laparoscopic procedure, patients were randomized to receive the transdermal scopolamine patch or placebo. ${ }^{49}$ The transdermal scopolamine patients had significantly lower incidences of nausea $(20.8 \%$ vs $62.5 \%, P=0.003)$ and of vomiting ( $8.3 \%$ vs $37.5 \%, P=0.016)$ in the first 24 hours following surgery. The number-needed-to-treat for nausea was 3 (95\% CI, 1.5-6.1), and the number-needed-to-treat for vomiting was 4 (95\% CI, 1.9-15.6).

\section{Early or late application of transdermal scopolamine}

The package labeling for transdermal scopolamine states that the patch should be applied behind the ear in the evening prior to surgery, except for cesarean section patients who should apply the patch an hour prior to the procedure. ${ }^{50}$ In actual clinical practice, application of the patch the night before surgery is not always feasible or convenient. Scopolamine patches are sometimes applied an hour or so before surgery (late application).

Early or late application does not appear to affect efficacy or tolerability as shown in a systematic review (23 randomized clinical trials, $n=1,963$ ) comparing early (night before surgery) versus late (same day as surgery) application. ${ }^{39}$ In another large systematic review ( 25 randomized clinical trials, $n=3,298$ ), transdermal scopolamine was similarly effective in preventing postoperative nausea when applied in the night before surgery (relative risk, 0.56 ; 95\% CI, $0.41-0.75, P<0.001$ ) or on the same day as surgery (relative risk $0.61,95 \% \mathrm{CI}, 0.47-0.79$, $P<0.001) .{ }^{40}$ Although late application may be considered an off-label use, it has been the subject of study and appears not to adversely affect the drug's safety or efficacy. It is a fairly common occurrence in actual clinical practice.

\section{Transdermal scopolamine safety}

The most common adverse events associated with transdermal scopolamine are associated with the agent's anticholinergic activity and are reversible upon cessation of use: visual disturbances, dry mouth, and dizziness, all of which tend to be mild. ${ }^{39}$ Sedation, confusion, and central cholinergic syndrome are other common adverse effects. ${ }^{40}$ Based on a systematic review $(n=1,963)$, out of 100 surgical patients using transdermal scopolamine, 18 will have some form of visual disturbances, eight will have dry mouth, two will be dizzy, and one will be agitated. ${ }^{39}$

Anticholinergic agitation can occur, specifically causing hallucinations, behavioral agitation, and/or delirium. Physostigmine is a reversible cholinesterase inhibitor that can cross the blood-brain barrier and may be helpful in treating scopolamine toxicity. ${ }^{51}$ Selective serotonin reuptake inhibitors may interact with transdermal scopolamine and exacerbate anticholinergic effects, leading to delayed emergence from anesthesia or symptoms of delirium or agitation. ${ }^{52}$

About $20 \%$ of patients using any type of transdermal drug delivery system (such as scopolamine, nitroglycerin, and fentanyl) report some form of adverse cutaneous side effects. ${ }^{53}$ These side effects are generally limited to the patch application site and are usually mild to moderate.

\section{Combination therapy}

Some clinicians recommend multimodal PONV/PDNV prophylactic therapy, which involves the use of two or more agents with different mechanisms of action. We report here 
on a few studies in the literature that incorporate transdermal scopolamine into combination therapy.

\section{Aprepitant}

In a clinical study of 120 patients (Apfel score $\geq 2$ ) who were scheduled to undergo elective surgery expected to last a minimum of 1 hour, patients were randomized to receive aprepitant alone or aprepitant block plus transdermal scopolamine for PONV prophylaxis in the first 24 hours following surgery. Aprepitant is known to block the emetic effects of substance $P$, a neurotransmitter in high concentration in the vomiting center of the brain. Investigators defined "complete response" as no incident of vomiting and no need for rescue medication during the study period; the rate of complete response was similar in both groups (63\% for aprepitant alone vs $57 \%$ for combination therapy, $P=0.57$ ). Likewise, results were similar for monotherapy versus combination therapy in terms of the percentage of patients who did not experience PONV and those who requested rescue medication. ${ }^{54}$

\section{Ondansetron}

Ondansetron $4 \mathrm{mg}$ intravenous (IV) may be combined with transdermal scopolamine for PONV/PDNV prophylaxis. ${ }^{18}$ In a randomized, double-blind, multicenter trial of 620 highrisk women undergoing outpatient laparoscopic or breast augmentation surgery, all patients received IV ondansetron $4 \mathrm{mg}$ 2-5 minutes before induction of anesthesia and a patch (one group received transdermal scopolamine, the other a sham patch). ${ }^{55}$ Patients on combination therapy (transdermal scopolamine plus ondansetron) had significantly less nausea and vomiting/retching at 24 hours after surgery, but not at 48 hours. Combination group patients used significantly less rescue medication ( $48 \%$ vs 39\%, $P<0.02$ ) and had significantly higher rates of "total response" (no nausea, no vomiting, no retching, no rescue medication) versus monotherapy patients, $35 \%$ vs $25 \%, P<0.01$.

Similar results were found in a single-center randomized controlled trial of 126 high-risk plastic surgery patients (significantly less PONV at 8-24 hours after surgery for patients with ondansetron plus transdermal scopolamine versus ondansetron alone). ${ }^{56}$ In a study of 56 high-risk patients who received ondansetron for PONV prophylaxis, the use of additional transdermal scopolamine was associated with a lower incidence of PONV $(P=0.043)$, longer time to first reported nausea $(P=0.044)$, longer time to first reported episode of emesis $(P=0.031)$, and less antiemetic medication consumption $(P=0.016) .{ }^{57}$ In a study of 37 patients undergoing uterine artery embolization, the addition of transdermal scopolamine to ondansetron prophylactic therapy for PONV was associated with a significant reduction in nausea incidence versus ondansetron alone (mean score of 1.8 vs 3.4 , respectively, $P=0.03$ ) in the first 24 hours after surgery. ${ }^{58}$ In study of 126 plastic surgery patients, all patients received ondansetron for PONV prophylaxis; patients were then randomized to receive transdermal scopolamine or a sham patch (placebo) 2 hours before surgery. About 8-24 hours after surgery, transdermal scopolamine patients exhibited a significant reduction in postoperative nausea. ${ }^{56}$

\section{Dexamethasone}

In a study of 120 orthopedic surgery patients, all patients were administered IV dexamethasone $8 \mathrm{mg}$ for PONV prophylaxis, and then the patients were randomized into three groups: one group also received IV ramosetron $0.3 \mathrm{mg}$ and one group received the transdermal scopolamine system. ${ }^{59}$ The scopolamine plus dexamethasone patients had a higher rate of complete remission of PONV (82.5\%) than the dexamethasone-only patients $(47.5 \%)$ or the dexamethasone-ramosetron patients $(50.0 \%)$. The authors concluded that transdermal scopolamine plus dexamethasone for PONV prophylaxis was the most effective prophylactic regimen in this study. ${ }^{59}$

\section{Transdermal scopolamine in special population Pediatric patients}

The pediatric population is not a homogeneous group, particularly as it relates to PONV prophylaxis. The risk of PONV or postoperative vomiting appears to be relatively low under the age of 3 years, but children over the age of 3 years may be at heightened risk for PONV and PDNV. Transdermal scopolamine is not approved for use in children under the age of 12 years. It should be noted that in many pediatric studies, investigators tend to report postoperative vomiting rather than PONV or postoperative nausea. This occurs because nausea is a subjective experience that children may be unable to report.

Studies in children demonstrate that transdermal scopolamine can effectively reduce postoperative vomiting in pediatric strabismus surgery patients ${ }^{60}$ and that it can reduce PONV in pediatric patients undergoing general anesthesia. ${ }^{61}$ These studies used a lower-dose patch than the one currently available $(0.25-0.75 \mathrm{mg})$. There is a need for better PONV/PDNV prophylaxis for pediatric surgical patients and transdermal scopolamine may be useful for older pediatric patients. However, transdermal drug delivery system is likely 
to remain inappropriate for neonates and babies, as their skin barrier is not yet fully mature. ${ }^{62}$

Risk factors for postoperative vomiting in pediatric patients differ from those of adults. For instance, smoking is not a useful risk factor for very young patients and sex does not appear to emerge as a risk factor until puberty. ${ }^{63}$ A pediatric risk assessment tool has identified risk factors for these young patients: age over 3 years, strabismus surgery, surgery lasting $\geq 30$ minutes, and history of postoperative vomiting or PONV in the patient, parents, or siblings. ${ }^{63}$ This new assessment tool was validated and possesses accuracy similar to the adult assessment scale. ${ }^{64}$

The role of transdermal scopolamine for the prevention of PONV in adolescents and older teenagers begs the question as to whether guidelines for adults or pediatric patients should apply. For weight-based dosing, it should be noted that many teenagers are physically as large as adults, and adult dosing may be considered. ${ }^{18}$

\section{Geriatric patients}

Older age confers a protective benefit in terms of the risk of PONV/PDNV. There are no particular restrictions in the use of transdermal scopolamine as PONV/PDNV prophylaxis in senior surgical patients.

\section{Pregnant and nursing patients}

Scopolamine crosses the placenta and should be used with clinical caution in pregnant women. Scopolamine is not considered to be teratogenic; it can be administered to lactating women. ${ }^{46}$

\section{Failed prophylaxis}

Consensus guidelines state that in patients for whom PONV/ PDNV prophylaxis has failed, an antiemetic agent from a different pharmacological class should be administered as rescue therapy. ${ }^{13,65}$ Thus, if transdermal scopolamine fails as a prophylactic agent, an agent from a different class should be administered as a rescue antiemetic.

\section{PONV/PDNV and the health care system}

The burden of PONV to the health care system is far from trivial - in fact, it may be the "little big problem." Patients with PONV require more time in the PACU than patients without (median, 235 minutes; range: 188-287 minutes, vs 171 minutes, range: $144-212$ minutes, $P=0.001) .{ }^{27} \mathrm{PONV}$ patients require significantly more nursing time ( 82 minutes, range: $63-106$, vs 68 minutes, range: $57-79, P=0.02$ ), which increases postoperative recovery costs (recovery costs PONV patient is $\$ 730$ vs $\$ 640$ for those without PONV, $P=0.006$, resulting in an incremental cost for PONV patients of $\$ 75$ ). PONV is also burdensome to patients and their families and significantly decreases quality of life ( $49 \%$ of PONV patients rated quality high in four domains vs $94 \%$ of patients without PONV, $P<0.001) .{ }^{27}$ This creates a serious financial burden, considering the tens of millions of surgeries in the US every year. Moreover, PDNV specifically has been associated with protracted recovery times, delayed discharge, and unexpected hospital admission after a planned outpatient procedure. ${ }^{6}$

Transdermal scopolamine appears to be a cost-effective PONV prophylactic agent, particularly in comparison to ondansetron and other expensive agents. Many antiemetics have been studied for cost-effectiveness in the setting of chemotherapy-induced nausea and vomiting; there are fewer studies for these agents specifically in postoperative use.

New quality metrics in US health care seek to elevate patient satisfaction with procedures. Although the Hospital Consumer Assessment of Healthcare Providers and Systems survey does not specifically address PONV, it is likely that episodes of PONV can decrease patient satisfaction with their procedure, and, in fact, reducing the PONV rates has been proposed as a straightforward method for hospitals to raise patient satisfaction scores generally. ${ }^{66}$

Transdermal scopolamine is not the only agent available for PONV/PDNV prophylaxis, but it offers distinct advantages. It is a well-known and well-studied drug that has an established body of evidence in support of its safety and efficacy in this setting. It is readily available, easy to apply, and comparatively inexpensive. The three-day efficacy of the patch may be useful as our growing knowledge of PONV and PDNV suggests that these conditions may not subside in the first 24 hours after surgery. Most patients tolerate the transdermal scopolamine patch well, although mild to moderate anticholinergic-type side effects (eg, blurry vision, dry mouth) may occur.

\section{Shortcomings}

The purpose of this communication was an update on the use, label and off-label, of transdermal scopolamine for PONV. This served as the inclusion criterion. There have been only a few new studies since publication of updated guidelines. Therefore, the emphasis was on inclusiveness, without formal quality evaluation of the evidence, etc. There was no attempt to the address cost-effectiveness of the therapy.

\section{Conclusion}

Transdermal scopolamine for the prevention of PONV and PDNV is hardly new, but a review of its use is timely, 
especially with the recent approval of generic version in the US. Despite major breakthroughs in modern surgical medicine, PONV and PDNV remain prevalent and PDNV may be far more common than we thought. PONV and PDNV are associated with significant patient distress and increased morbidity, posing a burden to the health care system. Effective prophylaxis is available, but it is impractical to treat all surgical patients, as the majority will not experience PONV/PDNV. Validated risk assessment tools exist and guidelines recommend providing prophylactic agents to those at moderate-to-high risk. Among the available prophylactic agents, transdermal scopolamine is the only agent available in patch form. As an anticholinergic agent, it is sometimes combined with other agents with different mechanisms of action in multimodal prophylactic therapy. "Early" versus "late" use of transdermal scopolamine (the night before versus hours before surgery, respectively) does not appear to affect the drug's efficacy or tolerability.

\section{Acknowledgment}

This manuscript was prepared with medical writing assistance from Jo Ann LeQuang of LeQ Medical, Houston, TX, Angleton, Texas.

\section{Author contribution}

All authors satisfy the author requirements set forth by the International Committee of Medical Journal Editors. All authors contributed toward data analysis, drafting and critically revising the paper and agree to be accountable for all aspects of the work.

\section{Disclosure}

The authors report no conflicts of interest in this work.

\section{References}

1. Mavridou P, Dimitriou V, Manataki A, Arnaoutoglou E, Papadopoulos G. Patient's anxiety and fear of anesthesia: effect of gender, age, education, and previous experience of anesthesia. A survey of 400 patients. JAnesth. 2013;27(1):104-108.

2. Macario A, Weinger M, Carney S, Kim A. Which clinical anesthesia outcomes are important to avoid? The perspective of patients. Anesth Analg. 1999;89(3):652-658.

3. Carvalho B, Cohen SE, Lipman SS, Fuller A, Mathusamy AD, Macario A. Patient preferences for anesthesia outcomes associated with cesarean delivery. Anesth Analg. 2005;101(4):1182-1187.

4. Kapur PA. The big "little problem". Anesth Analg. 1991;73(3): 243-245.

5. Apfel CC, Philip BK, Cakmakkaya OS, et al. Who is at risk for postdischarge nausea and vomiting after ambulatory surgery? Anesthesiology. 2012;117(3):475-486.

6. Kolodzie K, Apfel CC. Nausea and vomiting after office-based anesthesia. Curr Opin Anaesthesiol. 2009;22(4):532-538.
7. Odom-Forren J, Hooper V, Moser DK, et al. Postdischarge nausea and vomiting: management strategies and outcomes over 7 days. J Perianesth Nurs. 2014;29(4):275-284.

8. Obrink E, Jildenstal P, Oddby E, Jakobsson JG. Post-operative nausea and vomiting: update on predicting the probability and ways to minimize its occurrence, with focus on ambulatory surgery. Int J Surg. 2015;15C:100-106.

9. Fabling JM, Gan TJ, El-Moalem HE, Warner DS, Borel CO. A randomized, double-blinded comparison of ondansetron, droperidol, and placebo for prevention of postoperative nausea and vomiting after supratentorial craniotomy. Anesth Analg. 2000;91(2):358-361.

10. Lipp A, Kaliappan A. Focus on quality: managing pain and PONV in day surgery. Curr Anaesth Crit Care. 2007;18:200-207.

11. Feng PH, Chu KS, Lu IC, et al. Haloperidol plus ondansetron prevents postoperative nausea and vomiting in patients undergoing laparoscopic cholecystectomy. Acta Anaesthesiol Taiwan. 2009;47(1):3-9.

12. Apfel C, Laara E, Koivuranta M, Greim C, Rower N. A simplified risk score for predicting postoperative nausea and vomiting: conclusions from crossvalidations between two centers. Anaesthesiology. 1999;91: 693-700.

13. Gan TJ, Diemunsch P, Habib AS, Society for Ambulatory Anesthesia, et al. Consensus guidelines for the management of postoperative nausea and vomiting. Anesth Analg. 2014;118(1):85-113.

14. Fortier J, Chung F, Su J. Unanticipated admission after ambulatory surgery - a prospective study. Can J Anaesth. 1998;45:612-619.

15. Gold B, Kitz D, Lecky J, Neuhaus J. Unanticipated admission to the hospital following ambulatory surgery. J Am Med Assoc. 1989;262: 3008-3010.

16. Hill RP, Lubarsky DA, Phillips-Bute B, et al. Cost-effectiveness of prophylactic antiemetic therapy with ondansetron, droperidol, or placebo. Anesthesiology. 2000;92:958-967.

17. Tramer M. Strategies for postoperative nausea and vomiting. Best Practice and Research. Clin Anaesthesiol. 2004;18:693-701.

18. Pergolizzi JV, Raffa R, Taylor R. Prophylaxis of postoperative nausea and vomiting in adolescent patients: a review with emphasis on combination of fixed-dose ondansetron and transdermal scopolamine. J Drug Deliv. 2011;2011:426813.

19. Koivuranta M, Laara E, Snare L, Alahuhta S. A survey of postoperative nausea and vomiting. Anaesthesia. 1997;52:443-449.

20. Sinclair D, Chung F, Mezei G. Can postoperative nausea and vomiting be predicted? Anesthesiology. 1999;91:109-118.

21. Apfel CC, Heidrich FM, Jukar-Rao S, et al. Evidence-based analysis of risk factors for postoperative nausea and vomiting. Br J Anaesth. 2012;109(5):742-753.

22. Zhang L, Wang J, Chen C. Clinical studies of the relationship between the complication of cervicofacial rhytidectomy postoperative nausea and vomiting and different rhytidectomy sites. J Craniofac Surg. 2015; 26(2):e168-e172.

23. Hernandez Mateo MM, Martinez-Lopez I, Hernando-Rydings M, Revuelta-Suero S, Marques de Marino P, Serrano Hernando FJ. Systematic nasogastric tube in aortic surgery: is it necessary? Ann Vasc Surg. 2015;29(4):786-791.

24. Lichtor JL. Nausea and vomiting after surgery: it is not just postoperative. Curr Opin Anaesthesiol. 2012;25(6):673-679.

25. Le TP, Gan TJ. Update on the management of postoperative nausea and vomiting and postdischarge nausea and vomiting in ambulatory surgery. Anesthesiol Clin. 2010;28(2):225-249.

26. Odom-Forren J, Jalota L, Moser DK, et al. Incidence and predictors of postdischarge nausea and vomiting in a 7-day population. J Clin Anesth. 2013;25(7):551-559.

27. Parra-Sanchez I, Abdallah R, You J, et al. A time-motion economic analysis of postoperative nausea and vomiting in ambulatory surgery. Can J Anaesth. 2012;59(4):366-375.

28. Wesmiller SW, Bender CM, Sereika SM, et al. Association between serotonin transport polymorphisms and postdischarge nausea and vomiting in women following breast cancer surgery. Oncology Nurs Forum. 2014;41(2):195-202. 
29. Rowley M, Brown T. Postoperative vomiting in children. Anaesth Intensive Care. 1982;10:309-313.

30. Apfel CC, Korttila K, Abdalla M, IMPACT Investigators, et al. A factorial trial of six interventions for the prevention of postoperative nausea and vomiting. $N$ Engl J Med. 2004;350: 2441-2451.

31. Kranke P, Apefel CC, Papenfuss T, et al. An increased body mass index is no risk factor for postoperative nausea and vomiting. A systematic review and results of original data. Acta Anaesthesiol Scand. 2001;45: 160-166.

32. Charbit B, Albaladejo P, Funck-Brentano C, Legrand M, Samain E, Marty J. Prolongation of QTc interval after postoperative nausea and vomiting treatment by droperidol or ondansetron. Anesthesiology. 2005;102:1094-1100.

33. Tramer MR, Moore A, McQuay H. Meta-analytic comparison of prophylactic antiemetic efficacy for postoperative nausea and vomiting: propofol anaesthesia vs omitting nitrous oxide vs total iv anaesthesia with propofol. Br J Anaesth. 1997;78:256-259.

34. Apfel CC, Kranke P, Katz MH, et al. Volatile anaesthetics may be the main cause of early but not delayed postoperative vomiting: a randomized controlled trial of factorial design. Br J Anaesth. 2002;88(5): 659-668.

35. Roberts G, Bekker T, Carlsen H, Moffatt C, Slattery P, McClure A. Postoperative nausea and vomiting are strongly influenced by postoperative opioid use in a dose-related manner. Anesth Analg. 2005;101: 1343-1348.

36. Scuderi P, James R, Harris L, Mims GR. Multimodal antiemetic management prevents early postoperative vomiting after outpatient laparoscopy. Anesth Analg. 2000;91:1408-1414.

37. Apfel CC, Meyer A, Orhan-Sungur M, Jalota L, Whelan RP, JukarRao S. Supplemental intravenous crystalloids for the prevention of postoperative nausea and vomiting: quantitative review. $\mathrm{Br} J$ Anaesth. 2012;108(6):893-902.

38. Bailey PL, Streisand JB, Pace NL, et al. Transdermal scopolamine reduces nausea and vomiting after outpatient laparoscopy. Anesthesiology. 1990;72(6):977-980.

39. Kranke P, Morin AM, Roewer N, Wulf H, Eberhart LH. The efficacy and safety of transdermal scopolamine for the prevention of postoperative nausea and vomiting: a quantitative systematic review. Anesth Analg. 2002;95(1):133-143.

40. Apfel CC, Zhang K, George E, et al. Transdermal scopolamine for the prevention of postoperative nausea and vomiting: a systematic review and meta-analysis. Clin Ther. 2010;32(12):1987-2002.

41. Semple P, Madej TH, Wheatley RG, Jackson IJ, Stevens J. Transdermal hyoscine with patient-controlled analgesia. Anaesthesia. 1992;47(5):399-401.

42. Harris SN, Sevarino FB, Sinatra RS, Preble L, O'Connor TZ, Silverman DG. Nausea prophylaxis using transdermal scopolamine in the setting of patient-controlled analgesia. Obstet Gynecol. 1991;78(4): 673-677.

43. White PF, Tang J, Song D, et al. Transdermal scopolamine: an alternative to ondansetron and droperidol for the prevention of postoperative and postdischarge emetic symptoms. Anesth Analg. 2007;104(1):92-96.

44. Antor MA, Uribe AA, Erminy-Falcon N, et al. The effect of transdermal scopolamine for the prevention of postoperative nausea and vomiting. Front Pharmacol. 2014;5:55.

45. Samad A, Ullah Z, Alam MI, Wais M, Shams MS. Transdermal drug delivery system: patent reviews. Recent Pat Drug Deliv Formul. 2009; 3(2):143-152.

46. Renner UD, Oertel R, Kirch W. Pharmacokinetics and pharmacodynamics in clinical use of scopolamine. Ther Drug Monit. 2005;27(5): 655-665.

47. Harnett MJ, O’Rourke N, Walsh M, Carabuena JM, Segal S. Transdermal scopolamine for prevention of intrathecal morphineinduced nausea and vomiting after cesarean delivery. Anesth Analg. 2007;105(3):764-769.

48. Honkavaara P, Pyykko I, Rutanen EM. Increased incidence of retching and vomiting during periovulatory phase after middle ear surgery. Can J Anaesth. 1996;43(11):1108-1114.
49. Einarsson JI, Audbergsson BO, Thorsteinsson A. Scopolamine for prevention of postoperative nausea in gynecologic laparoscopy, a randomized trial. J Minim Invasive Gynecol. 2008;15(1):26-31.

50. DailyMed.com. Transderm Scop, Scopolamine Patch, Extended Release. Drug Label Information; 2014. Available from: http://dailymed.nlm. nih.gov/dailymed/drugInfo.cfm?setid=8e5dab9c-755b-460e-afe2-1 ddfc4acfd96. Accessed March 24, 2015.

51. Lin CH, Lung HL, Li ST, Lin CY. Delirium after transdermal scopolamine patch in two children. $J$ Neuropsychiatry Clin Neurosci. 2014;26(2):E01-E02.

52. Norton JA, Khabiri B, Arbona FL, Kover AJ. Possible central anticholinergic syndrome following transdermal scopolamine in an ambulatory surgery patient. Can J Anaesth. 2011;58(12):1149-1150.

53. Jenerowicz D, Polanska A, Olek-Hrab K, Silny W. Skin hypersensitivity reactions to transdermal therapeutic systems - still an important clinical problem. Ginekol Pol. 2012;83(1):46-50.

54. Green MS, Green P, Malayaman SN, Hepler M, Neubert LJ, Horrow JC. Randomized, double-blind comparison of oral aprepitant alone compared with aprepitant and transdermal scopolamine for prevention of postoperative nausea and vomiting. Br J Anaesth. 2012;109(5):716-722.

55. Gan TJ, Sinha AC, Kovac AL, et al. A randomized, double-blind, multicenter trial comparing transdermal scopolamine plus ondansetron to ondansetron alone for the prevention of postoperative nausea and vomiting in the outpatient setting. Anesth Analg. 2009;108(5):1498-1504.

56. Sah N, Ramesh V, Kaul B, Dalby P, Shestak K, Vallejo MC. Transdermal scopolamine patch in addition to ondansetron for postoperative nausea and vomiting prophylaxis in patients undergoing ambulatory cosmetic surgery. J Clin Anesth. 2009;21(4):249-252.

57. Jones S, Strobl R, Crosby D, Burkard JF, Maye J, Pellegrini JE. The effect of transdermal scopolamine on the incidence and severity of postoperative nausea and vomiting in a group of high-risk patients given prophylactic intravenous ondansetron. AANA J. 2006;74(2):127-132.

58. Lee JS, Costantino M, McCullough MF, et al. Transdermal scopolamine patch with odansetron for the control of nausea after uterine artery embolization compared with odansetron alone: results of a randomized placebo-controlled trial. J Vasc Interv Radiol. 2010;21(7): 1018-1023.

59. Lee HK, Lee JH, Chon SS, Ahn EK, Kim JH, Jang YH. The effect of transdermal scopolamine plus intravenous dexamethasone for the prevention of postoperative nausea and vomiting in patients with epidural PCA after major orthopedic surgery. Korean J Anesthesiol. 2010;58(1):50-55.

60. Horimoto Y, Tomie H, Hanzawa K, Nishida Y. Scopolamine patch reduces postoperative emesis in paediatric patients following strabismus surgery. Can J Anaesth. 1991;38:441-444.

61. Honkavaara P, Saarnivaara L, Klemola UM. Effect of transdermal hyoscine on nausea and vomiting after surgical correction of prominent ears under general anaesthesia. Br J Anaesth. 1995;74(6):647-650.

62. Delgado-Charro MB, Guy RH. Effective use of transdermal drug delivery in children. Adv Drug Deliv Rev. 2014;73:63-82.

63. Eberhart LH, Geldner G, Kranke P, et al. The development and validation of a risk score to predict the probability of postoperative vomiting in pediatric patients. Anesth Analg. 2004;99(6):1630-1637.

64. Kranke P, Eberhart LH, Toker H, Roewer N, Wulf H, Kiefer P. A prospective evaluation of the POVOC score for the prediction of postoperative vomiting in children. Anesth Analg. 2007;105(6):1592-1597.

65. Habib A, Gan T. The effectiveness of rescue antiemetics after failure of prophylaxis with ondansetron or droperidol: a preliminary report. J Clin Anesth. 2005;17:62-65.

66. Pergolizzi JV, Pappagallo M, LeQuang J, Labhsetwar S, Taylor R. New health care measures: emphasis on better management of postsurgical pain and postoperative nausea and vomiting. Hosp Pract (1995). 2014;42(1):65-74. 


\section{Publish your work in this journal}

Research and Reports in Transdermal Drug Delivery is an international, peer-reviewed, open access online journal publishing original research, study protocols, reviews, editorials and commentaries on all aspects of transdermal drug delivery. Specific topics in the journal include: Laboratory and clinical development of drug delivery systems including preclinical, clinical studies and protocols; Rationale and basic science; Drug delivery via gels, creams or patches; Use of chemical drug penetration enhancers; Patient acceptability studies; and pharmacoeconomic and clinical outcome studies. The manuscript management system is completely online and includes a very quick and fair peer-review system, which is all easy to use. Visit http://www.dovepress.com/ testimonials.php to read real quotes from published authors.

Submit your manuscript here: http://www.dovepress.com/research-and-reports-in-transdermal-drug-delivery-journal 